\title{
ELECTROCHEMICAL ACTIVITY OF LITHIUM NICKEL OXIDE THIN-FILM CATHODES OBTAINED BY ALD
}

\author{
${ }^{1}$ Ilya MITROFANOV, ${ }^{1}$ Yury KOSHTYAL, ${ }^{1}$ Denis NAZAROV, ${ }^{1}$ Ilya EZHOV, ${ }^{1}$ Artem KIM, \\ ${ }^{1,2}$ Aleksander RUMYANTSEV, ${ }^{1}$ Oleg MEDVEDEV, ${ }^{3}$ Oleksiy LYUTAKOV, ${ }^{1}$ Anatoliy POPOVICH, \\ ${ }^{1}$ Maxim MAXIMOV* \\ ${ }^{1}$ Peter the Great Saint-Petersburg Polytechnic University, Saint-Petersburg, Russia, maximspbstu@mail.ru \\ ${ }^{2}$ loffe Institute, Saint-Petersburg, Russia \\ ${ }^{3}$ Department of Solid State Engineering, Institute of Chemical Technology, Czech Republic, EU
}

https://doi.org/10.37904/nanocon.2020.3718

\begin{abstract}
Energy density is one of the essential characteristics of thin-film power sources which provides the duration of the autonomous performance of sensors, energy harvesters, loT devices, etc. The Atomic layer deposition (ALD) allows the growth of conformal coatings with a controlled composition on high aspect ratio substrates and can be used to manufacture some components of thin-film batteries. Modern high energy active cathode materials include Li, transition metal, and oxygen. The production of such films by the ALD method can be carried out using a linear combination of lithium oxide structures and transition metal oxide structures (supercycle approach), followed by annealing. The control of the composition and properties of the films can be achieved by varying the ratio of cycles conducted for deposition of binary oxides during supercycle. In present work, were used $1 / 10$ and 1/30 ratio of lithium oxide/nickel oxide ALD cycles during supercycle to obtain thin films of Li-Ni-O system. X-ray photoelectron spectroscopy of the as-deposited films demonstrates low nickel content in films. The annealed films at 800 and $900{ }^{\circ} \mathrm{C}$ for 10 minutes show the presence of the lithium silicates and nickel silicide phases. It was found that the best electrochemical performance show samples of LNO $1 / 30$ series annealed at $800^{\circ} \mathrm{C}$ : at a discharge current of $20 \mu \mathrm{A}(5 \mathrm{C})$, the capacity was equal to $35 \mu \mathrm{A} \cdot \mathrm{h} \cdot \mu \mathrm{m}^{-1} \cdot \mathrm{cm}^{-2}$. The obtained results demonstrate a low effect of an increase in the number of cycles on the proportion of nickel in the films and, consequently, on the electrochemical characteristics.
\end{abstract}

Keywords: Atomic layer deposition, lithium nickel oxide, Li-ion batteries, thin films

\section{INTRODUCTION}

The Internet of Things (IoT) is a rapidly growing area in which every object, thing, is a source of information and can communicate with other objects within the network [1,2]. Improving devices' performance in the Internet of Things requires miniature autonomous power supplies with increased lifetime, specific energy, and power. Solid-state lithium-ion batteries (SSLIBs) can be used to power loT devices[1,3,4]. The advantages of SSLIBs include a wide range of operating temperatures and safety. One of the critical characteristics of the SSLIBs is the specific energy, which ensures the duration of autonomous operation.

Since loT power supply can be mounted on printed circuit boards, the essential characteristics are the capacity, energy, and power density per specific mounting area $\left(A \cdot h / \mathrm{cm}^{2}, W \cdot h / \mathrm{cm}^{2}, W / \mathrm{cm}^{2}\right)$. These parameters can be improved by increasing the number of electrode pairs [5], the thickness of the electrodes, or by creating thinfilm batteries on high aspect structures (3D batteries) [6]. 
Another way to increase the specific energy is to create batteries using active anode and cathode materials with higher energy. Among the promising cathode materials that can be used for SSLIBs production are lithiated mixed oxides with high nickel content.

The ALD method allows the deposition of films of various compositions on substrates with a high aspect ratio trenches and can be used to obtain high-energy-density thin-film electrodes. Previously, it was shown that an electrochemically active film could be obtained by a linear combination of deposition cycles of lithium oxide and nickel oxide structures [7]. When using the ratio of the cycles of synthesis of lithium oxide structures and nickel oxide structures equal to $1 / 10$ or less, the atomic fraction of nickel was small and amounted to about $0.2 \%$ [7]. An increase of nickel content can be achieved by increasing the number of nickel oxide synthesis cycles in the supercycle. This work describes ALD synthesis and studies (physicochemical and electrochemical) of films obtained by ALD with a ratio of lithium oxide/nickel oxide synthesis cycles of $1 / 10$ and $1 / 30$.

\section{MATERIALS AND METHODS}

Monocrystalline silicon wafers (surface orientation 111, the diameter $40 \mathrm{~mm}$, Svetlana Co., LTD, SaintPetersburg, Russia) and stainless-steel plates (316SS, Tob New Energy Technology Co., LTD, diameter 15.8 $\mathrm{mm}$ ) were used as substrates. Before deposition, silicon substrates were cleaned in an ultrasonic bath in acetone and deionized water for $15 \mathrm{~min}$.

The deposition of lithium nickel oxide ( $\mathrm{Li}-\mathrm{Ni}-\mathrm{O}$ ) films was conducted by the ALD method using Picosun R-150 setup at $300{ }^{\circ} \mathrm{C}$ and at a base pressure in the reactor of 8-12 hPa. Lithium hexamethyldisilazide (LiHMDS, 97\%, Sigma Aldrich) and bis(cyclopentadienyl)nickel (II) (NiCp2, 99\% Sigma-Aldrich) were used as metalcontaining reagents. Remote oxygen plasma applied as a counter-reactant. The supercycle started with 10 or 30 nickel oxide structures (Ni-O, n) cycles deposition followed by one cycle of lithium oxide structures ( $\mathrm{Li}-\mathrm{O}$, $\mathrm{m})$ deposition. The conditions of $\mathrm{Li}-\mathrm{O}$ and $\mathrm{Ni}-\mathrm{O}$ deposition were selected, considering results reported elsewhere [8,9]. Deposition of lithium oxide system: $\mathrm{T}_{\text {source }}-160{ }^{\circ} \mathrm{C}$; pulse/purge with $\mathrm{N}_{2} /$ remote $\mathrm{O}_{2}$ plasma pulse/purge with $\mathrm{N}_{2}-0.1 / 6 / 15 / 6 \mathrm{~s}$. Deposition of nickel oxide system: $\mathrm{T}_{\text {source }}-110{ }^{\circ} \mathrm{C}$; pulse/purge with $\mathrm{N}_{2} /$ remote $\mathrm{O}_{2}$ plasma pulse/purge with $\mathrm{N}_{2}-1 / 10 / 15 / 10 \mathrm{~s}$. The Synthesized samples were heated in an oven for 10 minutes at $800-900{ }^{\circ} \mathrm{C}(\mathrm{T})$. The samples are denoted according to the following form of designation Li$\mathrm{Ni}-\mathrm{O} \mathrm{m} / \mathrm{nT}$.

The growth rates were calculated from film thickness measured by spectral ellipsometry $(350-1000 \mathrm{~nm})$ using Ellips-1891 SAG ellipsometer (CNT, Novosibirsk, Russia).

X-ray photoelectron spectra (XPS) were registered with a Thermo Fisher Scientific Escalab 250Xi spectrometer in the Physical Methods of Surface Investigation Resource Centre, SPbSU (Thermo Fisher, Waltham, MA, USA). Before performing the first measurement, the surface layer of samples was etched by $\mathrm{Ar}+$ ions with $500 \mathrm{eV}$ energy for $30 \mathrm{~s}$ to remove adventitious carbon. The samples were excited by Al-Ka $(1486.7 \mathrm{eV}) \mathrm{X}$-rays in the vacuum of $7 \times 10^{-8} \mathrm{~Pa}$. The sample charging was automatically compensated.

X-ray diffraction (XRD) studies in surface-sensitive grazing incidence XRD (GIXRD) modes were performed using a Bruker D8 DISCOVER (Cu-Ka, Billerica, MA, USA) high-resolution diffractometer.

The electrochemical performance of 316SS substrates with deposited Li-Ni-O films was studied in CR2032 coin cells. Lithium foil, polyolefin porous film 2325 (Celgard, Charlotte, NC, USA), and TC-E918 (Tinci, Guangzhou, China) were used as the counter electrode, separator, and electrolyte, respectively. Coin cells were assembled in an argon glove box OMNI-LAB (VAC). Cyclic voltammetry (CV) was performed using a potentiostat PGSTAT302N+ (Autolab, Utrecht, the Netherlands) in the range of $2.5-4.3 \mathrm{~V}$ with a scan rate of $0.5 \mathrm{mV} / \mathrm{s}$. Cyclic charge/discharge was performed using the battery testing system CT-3008W-5V10mA (Neware, Shenzhen, China) at room temperature in the potential range of $2.5-4.3 \mathrm{~V}$, at current $20-80 \mu \mathrm{A}$. 


\section{RESULT AND DISCUSSION}

\subsection{Films deposition and thermal treatment}

The program for the synthesis of films is summarized in Table 1. For both series of samples, the growth per supercycle determined from thickness of films measured by spectral ellipsometry was lower than calculated from linear combination of growth per rate of lithium oxide ( $\mathrm{LiOx}-1.23 \pm 0.01-\AA$ / cycle [9]) and nickel oxide (NiO $-0.12 \pm 0.01 \AA$ / cycle [8]). The difference between values augmented with the increase of nickel oxide deposition cycles in the supercycle. Therefore, we assume that Li-contained species grafted on the surface may slow nickel oxide structure growth.

Table 1 Synthesis program and thin films growth characteristics

\begin{tabular}{|c|c|c|c|c|c|c|c|}
\hline \multirow{2}{*}{ Name } & \multicolumn{2}{|c|}{ Cycles } & \multirow{2}{*}{ Supercycles/Cycles } & \multicolumn{3}{c|}{ Growth per cycle/supercycle, $\boldsymbol{A}$} \\
\cline { 6 - 9 } & \multicolumn{2}{|c}{} & & \multicolumn{2}{c|}{ Calculation } & \multicolumn{2}{c|}{ Ellipsometry } \\
\cline { 2 - 6 } & Li-Ox & Ni-Ox & & SC & C & SC & C \\
\hline LNO 1/10 & 1 & 10 & $250 / 2750$ & 2.56 & 0.23 & 2.32 & 0.21 \\
\hline LNO 1/30 & 1 & 30 & $175 / 5250$ & 4.56 & 0.14 & 3.06 & 0.1 \\
\hline
\end{tabular}

The stainless-steel substrates with deposited structures were investigated by XPS analysis (Figure 1). It was found that for both series of samples, atoms of carbon, lithium, and oxygen are presented in significant quantities on the films external surface. The presence of Carbon may be due to adsorbed hydrocarbon and carbonate impurities as well as residues of Carbon from precursor ligand. The quantiles of nickel and silicon are moderate and don't exceed 2.3 at.\%. The concentration of nickel (0.7 at.\%) on the surface of LNO 1/30 is 3.5 times higher than for LNO $1 / 10$ but still not sufficient to form the stoichiometric LiNiO2 phase.

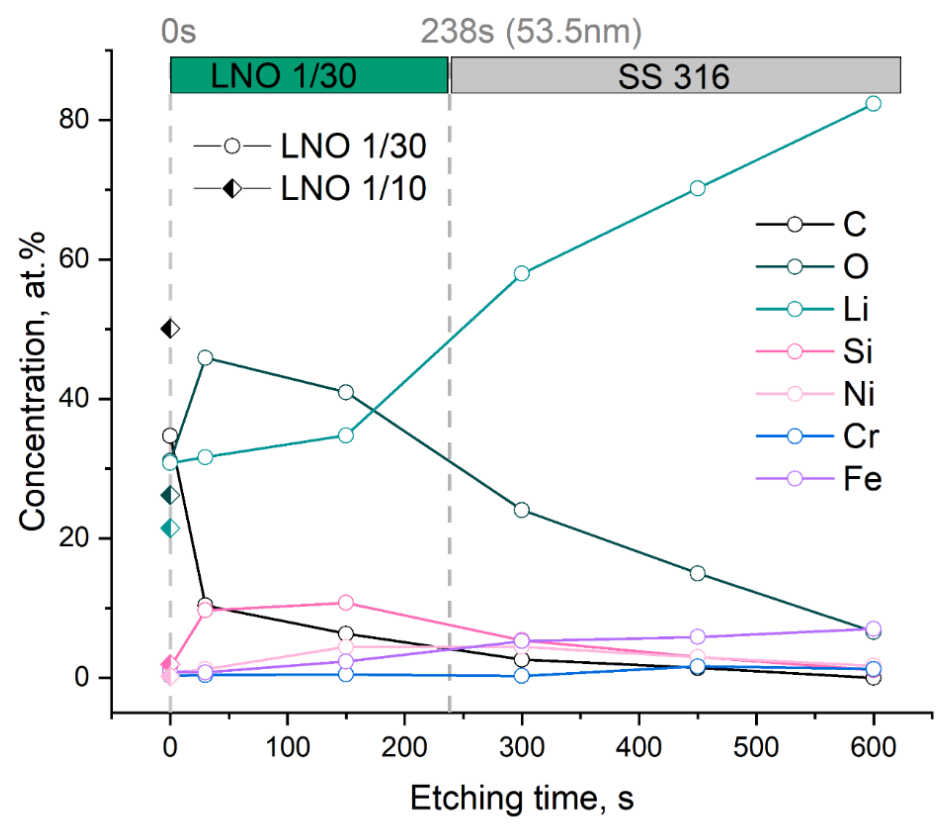

Figure 1 Concentration depth profile measured by X-ray photoelectron (XPS)

The LNO 1/30 sample was investigated by XPS after different times of etching ( $3 \mathrm{keV}$ ). The rate of etching determined for model samples of similar composition was $0.225 \mathrm{~nm} / \mathrm{s}$. Thus, the maximal etching time $(600 \mathrm{~s})$ exceeds the etching time required for reaching the substrate. 
After 30 seconds of etching, the quantity of carbon decreases significantly (from 32 to 10 at.\%) and declines moderately with subsequent etching time. According to calculated data, the deposited films' carbon content is varied from 5 to 10 at.\%, and its presence may be due to ligand residues. The quantity of nickel slightly increased from 0.7 at.\% to 4.5 at.\%, but the increment may be due to nickel content in the stainless-steel substrate. The concentration of silicon in the films reaches 11 at.\%. Thus, the ligand of the LiHMDS precursor also is not entirely removed during plasma treatment. Lithium (1s) and Iron (3p) bands in XPS spectra are superimposed, and the increment of lithium shown in Figure 1 may be explained by the contribution of iron from the substrate. Nevertheless, one can conclude that lithium's atomic concentration is much higher than other elements' concentrations.

The as-deposited thin films exhibited no reflexes on XRD patterns. Therefore, no detectable crystal phase was observed in the films. On the diffractograms of the samples obtained after thermal treatment at $800-900{ }^{\circ} \mathrm{C}$ for 10 minutes, several reflexes have appeared. The observed reflexes could be assigned to silicon support and the phases of lithium silicates and nickel silicide $\left(\mathrm{L}_{2} \mathrm{O}_{5} \mathrm{Si}_{2}\right.$ [PDF-2 00-030-0767], $\mathrm{Li}_{2} \mathrm{SiO}_{3}$ [ $\mathrm{Li}_{2} \mathrm{SiO}_{3} \mathrm{PDF}$ 01-0700330] NiSi2 [PDF 01-077-9324]). Since a deposited film contains silicon (Figure 2), the lithium silicates can be formed due to phase transformation in film and not due to the interaction of deposited film and a silicon substrate. Nickel silicide could be formed due interaction of nickel and silicon substrate. The reflexes of $\mathrm{NiO}$ (PDF 01-071-1179) и $\mathrm{LiNiO}_{2}$ (PDF 00-062-0468) were not found on the roentgenograms. Probably contained nickel, lithium, and oxygen phases are not formed during deposition, and subsequent calcination or their quantity is the bellow of the detection limit.

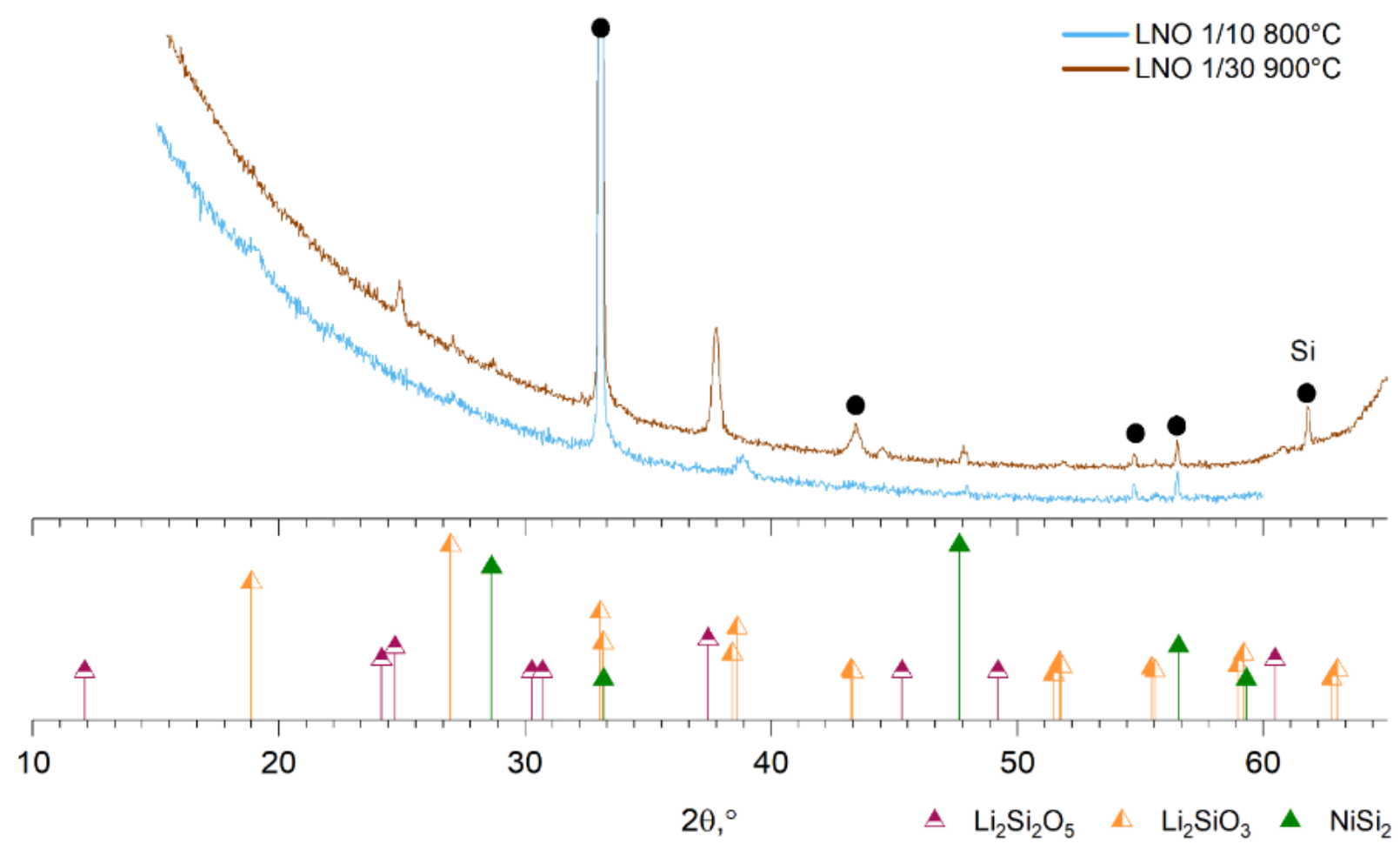

Figure 2 XRD patterns of LNO 1/10 and LNO 1/30

\subsection{Electrochemical performance}

According to the results of nickel-containing cathode materials investigations using cyclic voltammetry [10] the maximum current increase is observed in $4.15-4.25 \mathrm{~V}$ region of the anode curve. It corresponds to the oxidation of nickel $\left(\mathrm{Ni}^{2+} / \mathrm{Ni}^{3+} / \mathrm{Ni}^{4+}\right)$. During the reverse process, the current increases at $4.2 \mathrm{~V}\left(\mathrm{Ni}^{4+} / \mathrm{Ni}^{3+}\right)$ and $3.65-3.75 \mathrm{~V}$ regions $\left(\mathrm{Ni}^{3+} / \mathrm{Ni}^{2+}\right)$. Although both regions with increment of current are observed in cyclic voltammetry of 
samples only after calcination taking into account the nickel quantity it is possible that observed increment of current characterizes other phases electrochemical activity such as lithium silicates.

The charge/discharge at various C-rate was performed after 15 cycles of $\mathrm{CV}$ measurement. To compare the performance of films, the specific volumetric $\left(\mu \mathrm{Ah} \cdot \mu \mathrm{m}^{-1} \cdot \mathrm{cm}^{-2}\right)$ discharge capacities were used. At higher discharge currents, all samples showed a lower discharge capacity. The LNO-1/30 samples showed higher discharge capacities at various C-rates (Figure 3). As deposited, films have not possessed any notable electrochemical activity and could not store energy. For both series of the sample, the higher discharge capacity exhibit samples calcinated at $800^{\circ} \mathrm{C}$. The calcination at $900^{\circ} \mathrm{C}$ led to a small decrease in discharge capacity. The capacity observed at moderate discharge currents $(20 \mu \mathrm{A}, 5-7 \mathrm{C})$ varied from $23 \mu \mathrm{Ah} \cdot \mu \mathrm{m}^{-1} \cdot \mathrm{cm}^{-2}$ $\left(\mathrm{LNO} 1 / 10900^{\circ} \mathrm{C}\right)$ to $35 \mu \mathrm{Ah} \cdot \mu \mathrm{m}^{-1} \cdot \mathrm{cm}^{-2}\left(\mathrm{LNO} 1 / 30800^{\circ} \mathrm{C}\right)$ and less than the calculated value from density and specific gravimetrical capacity for $\mathrm{LiNiO}_{2}$ film $-103 \mu \mathrm{Ah} \cdot \mu \mathrm{m}^{-1} \cdot \mathrm{cm}^{-2}$ (at $0.5 \mathrm{C}$ discharge rate [7,11]). The lower discharge capacities of deposited films may be due to another active compound (smaller nickel content) and higher discharge rates.

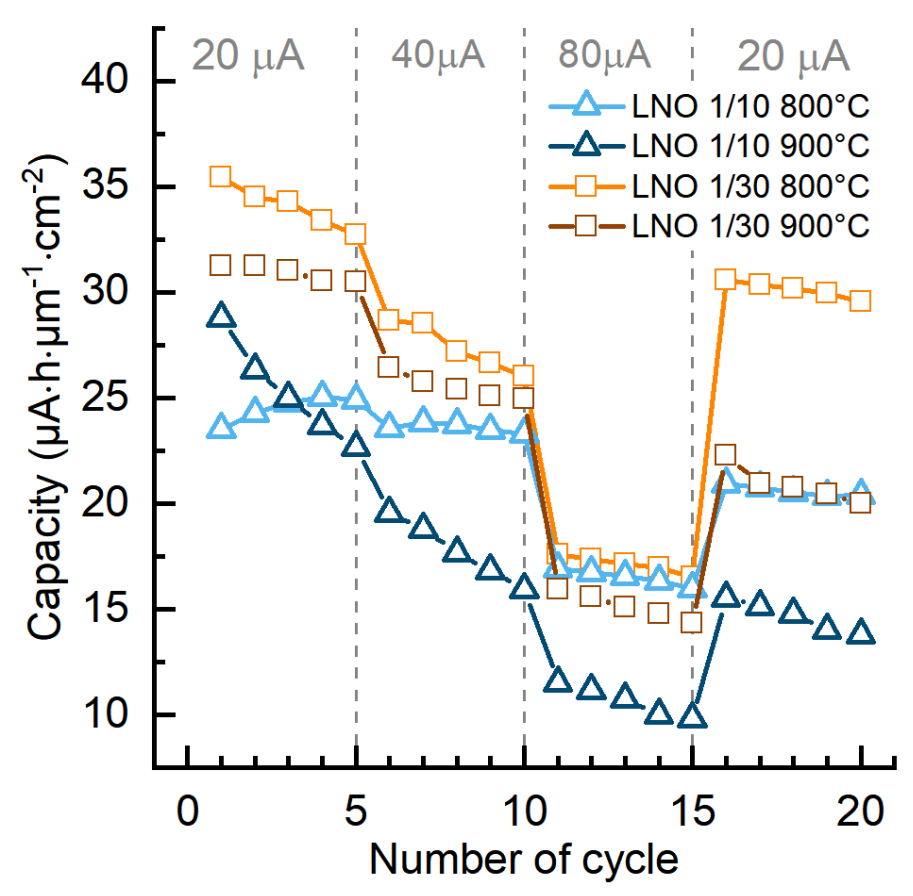

Figure 3 The effect of discharge current on the capacity of annealed LNO 1/10 and LNO 1/30 samples

\section{CONCLUSION}

With the use of $\mathrm{LiHMDS}, \mathrm{NiCp}_{2}, \mathrm{O}_{2}$ (remote plasma) precursors, and the supercycle approach, the thin films were deposited at $300^{\circ} \mathrm{C}$ by Atomic layer deposition on the silicon and stainless steel substrates. The growth of $\mathrm{NiO}$ structures is hindered by $\mathrm{LiHMDS} / \mathrm{O}_{2}$ treatment. The increase of $\mathrm{NiO}$ cycles deposition from 10 to 30 in supercycle led to an augmentation of nickel content from 0.2 at.\% to 0.7 at. $\%$ at surface $(4.5$ at. \% in the depth of the film - LNO 1/30). According to XPS results, the films are contaminated by silicon and carbon - lithium and nickel precursors' residues. The as-deposited films were amorphous. Calcination of films for 10 minutes at 800 and $900^{\circ} \mathrm{C}$ led to a probable formation of lithium silicate phases and $\mathrm{NiSi}_{2}$. Before thermal treatment, the synthesized films have not possessed any electrochemical activity. After annealing, the discharge capacity increased to $32-35 \mu \mathrm{Ah} \cdot \mu \mathrm{m}^{-1} \cdot \mathrm{cm}^{-2}$ at 5-7C rate currents, which is smaller than the estimated value for $\mathrm{LiNiO}_{2}$ $-103 \mu \mathrm{Ah} \cdot \mu^{-1} \cdot \mathrm{cm}^{-2}(0.5 \mathrm{C})$ possible due to low content of electrochemical active phase and higher discharge rate. 


\section{ACKNOWLEDGEMENTS}

\section{The research was conducted under the financial support of the Russian Science Foundation grant (project No. 18-73-10015).}

\section{REFERENCES}

[1] SHIRVANIMOGHADDAM, M., SHIRVANIMOGHADDAM, K., ABOLHASANI, M.M., FARHANGI, M., BARSARI, V.Z., LIU, H.Y., DOHLER, M., NAEBE, M. Towards a Green and Self-Powered Internet of Things Using Piezoelectric Energy Harvesting. leee Access. [online]. 2019, vol. 7, pp. 94533-94556. doi: 10.1109/access.2019.2928523.

[2] GOLDSTEIN, M. IEEE Computer Society Phoenix Chapter - Internet of Things Innovations \& Megatrends Update. [online]. [viewed 2020.09.25]. Available from: https://www.slideshare.net/markgirc/ieee-computer-society-phoenixchapter-internet-of-things-innovations-megatrends-update-121119

[3] MAXIMOV, M.Y., NOVIKOV, P.A., NAZAROV, D.V., RYMYANTSEV, A.M., SILIN, A.O., ZHANG, Y., POPOVICH, A.A. Characterization and Electrochemical Performance at High Discharge Rates of Tin Dioxide Thin Films Synthesized by Atomic Layer Deposition. Journal of Electronic Materials. [online]. 2017, vol. 46, pp. 6571-6577. Available from: https://doi.org/10.1007/s11664-017-5701-8.

[4] MAXIMOV, M.Y., KOSHTYAL, Y., MITROFANOV, I., EZHOV, I., RUMYANTSEV, A., POPOVICH, A. Features of the synthesis of lithium-based ternary oxide nanofilms by atomic layer deposition with LHMDS for thin-film LIBs. Materials Today-Proceedings. [online]. 2020, vol. 25, pp. 6-12. Available from: https://doi.org/10.1016/j.matpr.2019.10.107.

[5] PEARSE, A., SCHMITT, T., SAHADEO, E., STEWART, D.M., KOZEN, A., GERASOPOULOS, K., TALIN, A.A., LEE, S.B., RUBLOFF, G.W., GREGORCZYK, K.E. Three-Dimensional Solid-State Lithium-Ion Batteries Fabricated by Conformal Vapor-Phase Chemistry. Acs Nano. [online]. 2018, vol. 12, pp. 4286-4294. Available from: https://doi.org/10.1021/acsnano.7b08751.

[6] OUDENHOVEN, J.F.M., BAGGETTO, L., NOTTEN, P.H.L. All-Solid-State Lithium-lon Microbatteries: A Review of Various Three-Dimensional Concepts. Advanced Energy Materials. [online]. 2011, vol. 1, pp 10-33. Available from: https://doi.org/10.1002/aenm.201000002.

[7] MAXIMOV, M., NAZAROV, D., RUMYANTSEV, A., KOSHTYAL, Y., EZHOV, I., MITROFANOV, I., KIM, A., MEDVEDEV, O., POPOVICH, A. Atomic Layer Deposition of Lithium-Nickel-Silicon Oxide Cathode Material for Thin-Film Lithium-Ion Batteries. Energies. [online]. 2020, vol. 13, 2345. Available from: https://doi.org/10.3390/en13092345.

[8] KOSHTYAL, Y., NAZAROV, D., EZHOV, I., MITROFANOV, I., KIM, A., RYMYANTSEV, A., LYUTAKOV, O., POPOVICH, A., MAXIMOV, M. Atomic Layer Deposition of NiO to Produce Active Material for Thin-Film LithiumIon Batteries. Coatings. [online]. 2019, vol. 9, 301, Available from: https://doi.org/10.3390/coatings9050301

[9] NAZAROV, D., EZHOV, I., MITROFANOV, I., LYUTAKOV, O., MAXIMOV, M.Y. The Use of the TMA as Stabilizing Reagent for the Li-O System Obtained by Atomic Layer Deposition. Key Engineering Materials. [online]. 2019, vol. 822, pp.787-794. Available from: https://doi.org/10.4028/www.scientific.net/KEM.822.787.

[10] CHONG, S.K., LIU, Y.N., YAN, W.W., CHEN, Y.Z. Effect of valence states of Ni and Mn on the structural and electrochemical properties of Li1.2NixMn0.8-xO2 cathode materials for lithium-ion batteries. Rsc Advances. [online]. 2016, vol. 6, pp. 53662-53668. Available from: https://doi.org/10.1039/c6ra09454f.

[11] REMPEL, J., PULLEN, A., KAPLAN, D., BARNETT, B., SRIRAMULU, S. High-Nickel Cathode / Graphite Anode Cells for Diverse DoD Applications (24-1). In: Proceedings of 48th Power Sources Conference. Marriott Tech Center Hotel, Denver, Colorado, 2018, pp. 404-407. 